\title{
Airclad fiber laser technology
}

Hansen, Kim P.; Olausson, Christina Bjarnal Thulin; Broeng, Jes; Noordegraaf, Danny; Maack, Martin D.; Alkeskjold, Thomas Tanggaard; Laurila, Marko; Nikolajsen, Thomas; Skovgaard, Peter M. W.; Sørensen, Mads Hoy

Total number of authors:

13

Published in:

Optical Engineering

Link to article, DOI:

10.1117/1.3631872

Publication date:

2011

Document Version

Publisher's PDF, also known as Version of record

Link back to DTU Orbit

Citation (APA):

Hansen, K. P., Olausson, C. B. T., Broeng, J., Noordegraaf, D., Maack, M. D., Alkeskjold, T. T., Laurila, M.,

Nikolajsen, T., Skovgaard, P. M. W., Sørensen, M. H., Denninger, M., Jakobsen, C., \& Simonsen, H. R. (2011). Airclad fiber laser technology. Optical Engineering, 50(11), 111609. https://doi.org/10.1117/1.3631872

\section{General rights}

Copyright and moral rights for the publications made accessible in the public portal are retained by the authors and/or other copyright owners and it is a condition of accessing publications that users recognise and abide by the legal requirements associated with these rights.

- Users may download and print one copy of any publication from the public portal for the purpose of private study or research.

- You may not further distribute the material or use it for any profit-making activity or commercial gain

- You may freely distribute the URL identifying the publication in the public portal 


\section{Optical Engineering}

\section{Airclad fiber laser technology}

Kim P. Hansen

Christina B. Olausson

Jes Broeng

Danny Noordegraaf

Martin D. Maack

Thomas Tanggaard Alkeskjold

Marko Laurila

Thomas Nikolajsen

Peter M. W. Skovgaard

Mads Hoy Sørensen

Mark Denninger

Christian Jakobsen

Harald R. Simonsen 


\section{Airclad fiber laser technology}

\author{
Kim P. Hansen \\ NKT Photonics A/S \\ Blokken 84 \\ Birkeroed, DK-3460 Denmark
}

\author{
Christina B. Olausson \\ NKT Photonics A/S \\ Blokken 84 \\ Birkeroed, DK-3460 Denmark \\ and \\ DTU Fotonik \\ Ørsteds Plads \\ Building 343 \\ Kgs. Lyngby, DK-2800 Denmark
}

\section{Jes Broeng}

NKT Photonics A/S

Blokken 84

Birkeroed, DK-3460 Denmark

E-mail: jb@nktphotonics.com

\author{
Danny Noordegraaf \\ NKT Photonics A/S \\ Blokken 84 \\ Birkeroed, DK-3460 Denmark \\ and \\ DTU Fotonik \\ Ørsteds Plads \\ Building 343 \\ Kgs. Lyngby, DK-2800 Denmark
}

\author{
Martin D. Maack \\ Thomas Tanggaard Alkeskjold \\ NKT Photonics A/S \\ Blokken 84 \\ Birkeroed, DK-3460 Denmark
}

\author{
Marko Laurila \\ DTU Fotonik \\ Ørsteds Plads \\ Building 343 \\ Kgs. Lyngby, DK-2800 Denmark
}

Thomas Nikolajsen

Peter M. W. Skovgaard

Mads Hoy Sørensen

Mark Denninger

Christian Jakobsen

Harald R. Simonsen

NKT Photonics A/S

Blokken 84

Birkeroed, DK-3460 Denmark Abstract. High-power fiber lasers and amplifiers have gained
tremendous momentum in the last 5 years. Many of the

0091-3286/2011/\$25.00 (c) 2011 SPIE traditional manufacturers of gas and solid-state lasers are now pursuing the fiber-based systems, which are displacing the conventional technology in many areas. High-power fiber laser systems require reliable fibers with large cores, stable mode quality, and good power handling capabilitiesrequirements that are all met by the airclad fiber technology. In the present paper we go through many of the building blocks needed to build high-power systems and we show an example of a complete airclad laser system. We present the latest advancements within airclad fiber technology including a new $100 \mu \mathrm{m}$ single-mode polarization-maintaining rod-type fiber capable of amplifying to megawatt power levels. Furthermore, we describe the novel airclad-based pump combiners and their use in a completely monolithic $350 \mathrm{~W}$ cw fiber laser system with an $M^{2}$ of less than 1.1. (C) 2011 Society of Photo-Optical Instrumentation Engineers (SPIE). [DOI: 10.1117/1.3631872]

Subject terms: airclad fibers; photonic crystal fibers; high-power fiber lasers.

Paper 110401SSPR received Apr. 20, 2011; revised manuscript received Jul. 21, 2011; accepted for publication Aug. 8, 2011; published online Oct. 13, 2011.

\section{Introduction}

Traditional active fibers, like those used for telecommunication amplifiers, are standard transmission fibers where the core region has been doped with rare earth ions. This fiber type is preferably pumped with single-mode pump lasers directly in the signal core. The power limitations of singlemode pump sources make this type of fiber unsuitable for high-power applications. Consequently, high-power fibers are designed with a double-cladding structure, where a second low index region acts as cladding for a large pump core. In the center of the pump core is located a smaller doped signal core. The major advantage of the double-cladding design, over the more traditional core pumped variety, is the large pump area and high numerical aperture (NA), enabling pumping with low-cost multimode diodes. ${ }^{1}$

Standard double-cladding fibers utilize a low-index polymer coating to create the cladding for the pump core. The obtainable refractive index of the polymer limits the numerical aperture of the fibers (in praxis to below 0.48). In order to conserve the brightness acceptance of the fiber, a larger cladding area is required, thus reducing the core/clad ratio, and thereby limiting the pump absorption per fiber length and how short a fiber can be made. Moreover, the polymer material itself poses a challenge in high-power systems due to the risk of degradation at high pump powers and elevated temperatures. ${ }^{2,3}$ Polymer clad fibers capable of sustaining a higher power level can be achieved with the triple-clad design where the pump cladding is formed by two low index areas. The inner area is made of F-doped glass creating a $0.2 \mathrm{NA}$ inner cladding that can withstand very high power levels. The F-layer is then coated with the usual low index polymer to reach 0.48 NA. The 0.2 pump cladding limits the amount of light reaching the polymer, thereby reducing the thermal load there.

The photonic crystal fiber (PCF) equivalent to the doubleclad fiber is the airclad large mode area (LMA) fiber shown 


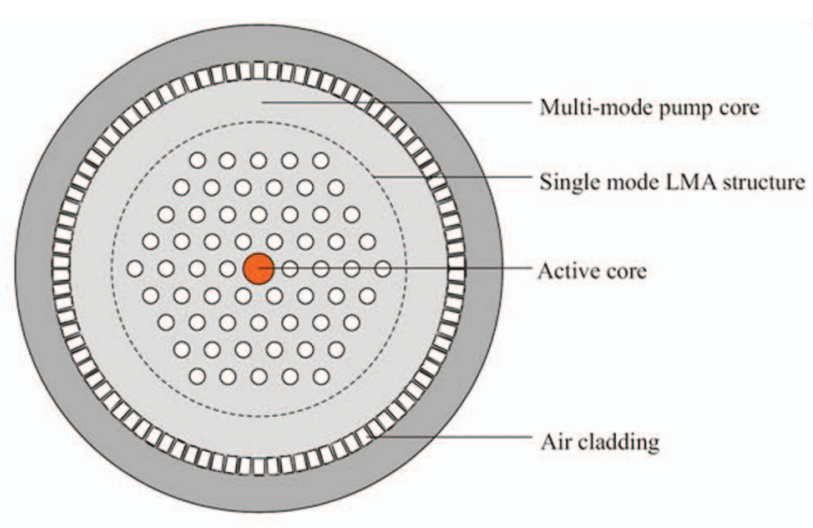

(a)



(b)

Fig. 1 (a) Structure of an airclad fiber comprising an active core surrounded by a single-mode LMA structure, a multimode pump core and an air cladding. (b) The numerical aperture of the airclad is determined by the bridge width, $\Delta$, and is typically chosen to be in the range 0.55 to 0.65 . Higher numerical apertures are possible but at the expense of cleavability and handling of the fibers.

in Fig. 1(a). The fiber consists of an LMA structure with an active, doped core placed inside an airclad pump guide. Due to the large index contrast, the airclad can provide very large numerical apertures determined by the bridge width in the airclad as shown in Fig. 1(b). Consequently, the NA is only limited by the practical handling of the fibers where cleaving of the fibers becomes increasingly challenging at NAs above 0.6 (the exact limit depends on fiber design and cleaving equipment and can, for some designs, be as high as 0.7 while still maintaining good cleavability). Moreover, as the fiber is air-glass, the thermal conductivity is greatly improved compared to polymer-clad fibers, and there is no material degradation. ${ }^{4}$ The power density is only limited by the damage threshold of silica. The combinations of a very large mode field diameter (MFD) and high NA makes it possible to create lasers and amplifiers with very short fiber lengths, drastically reducing the nonlinear effects (see also Sec. 4).

In this paper, the latest results within airclad fiber laser technology will be presented, starting with the particular core characteristics of photonic crystal fibers for high-power applications, followed by the latest advancements in active polarizing fibers and rod-type fibers designed for extreme high-power systems. Finally, we will describe a new class of airclad pump combiners and their use in a completely monolithic $\mathrm{CW}$ airclad fiber laser system.

\section{Core Properties}

Restrictions on the power of fibers lasers are mainly due to nonlinear effects, which scale as the product of power density and fiber length. Thus, progress in the reduction of nonlinearities entails shorter fibers and larger mode area fibers in order to reduce the power density. Furthermore, stable fundamental mode operation is only possible in single-mode fibers. The stability is desired both in terms of temporal stability (operation over several thousand of hours), temperature stability (industrial lasers should run reliably in varying environmental conditions, with particular importance for frequency converting systems), and power stability (lasers should be able to run stable at different power levels). The standard step-index core technology limits the mode field diameter to around $15 \mu \mathrm{m}$ for single-mode operation due to the limited index uniformity across the core and the challenges involved in achieving a sufficiently small index step to prevent higher order mode guidance. Larger cores can be made, but such fibers typically rely on tight coiling to obtain single-mode operation, which can cause instabilities and mode distortion. ${ }^{5}$

The single-mode range of the photonic crystal fiber is analyzed by considering the effective refractive index of the cladding, where the air holes serve as modal filters. If the relative hole size $d / \Lambda$ increases, more higher-order modes will be guided and, as a consequence, the number of guided modes can be determined solely by the cladding geometry, independent of wavelength and core diameter. ${ }^{6}$ It has been shown that the photonic crystal fiber can be single-mode at all wavelengths and, thus, theoretically the core can become arbitrarily large, only limited by bending losses, ${ }^{7}$ but in reality the limitations to the core size are defined by macro- and microbending losses. ${ }^{8-11}$ A mechanically stable large mode area fiber resistant to bending losses is found in the rod design, which features the dimensions of a rod, in the range of a few millimeters, and a strongly reduced fiber length (see Sec. 4).

The incorporation of a doped core will increase the effective index of refraction. However, in general the core is co-doped with fluorine to compensate for the refractive index increase. This provides a refractive index of the core that is closely matched to silica, and therefore the guiding properties can still be determined by the photonic crystal structure surrounding the core and not by the index step due to the dopants.

The high beam quality is one of the virtues of a fiber laser and is often quantified through the $M^{2}$ value. However, it has been shown that a low $M^{2}$ number is not a guarantee for single-mode operation since the $M^{2}$ value can be impacted by several parameters such as signal light in the pump cladding and the relative phase between the fiber modes. ${ }^{12}$ Recently, a new method described by Nicholson et al. ${ }^{13}$ uses spatial and spectral $\left(S^{2}\right)$ resolved interferometry to spatially resolve propagating modes and their relative intensities. This method can be directly applied for measuring the higher order mode (HOM) suppression of optical fibers. Two or more modes propagating in an optical fiber form a spatial and spectral interference pattern if the modes have different group velocities. The $S^{2}$ imaging method analyzes this interference pattern and can detect small quantities of HOMs interfering with the 


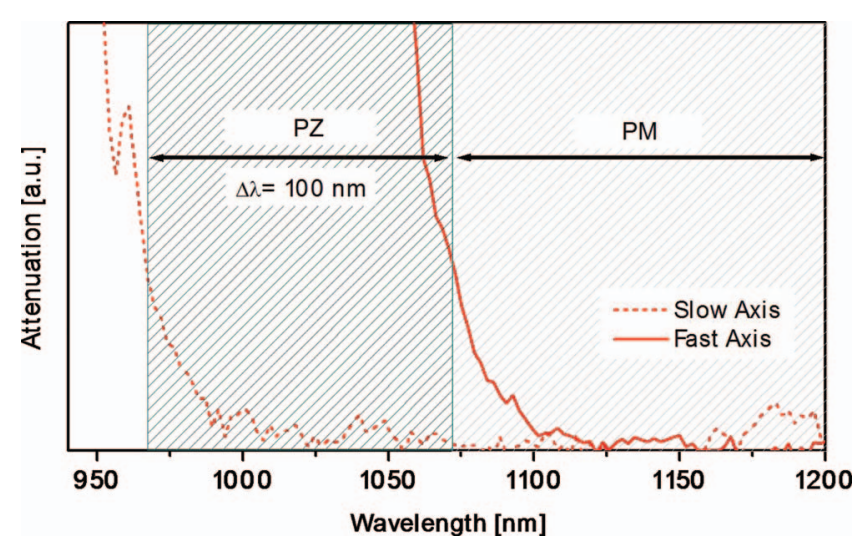

Fig. 2 Polarization properties of a large mode area, high NA, airclad fiber containing stress applying parts for polarization control. The polarization properties are controlled by the exact bending radius and the orientation of the fiber.

fundamental mode. No a priori knowledge of the fiber properties are required to fully quantify the modal shape of the different modes and their relative intensities and phases.

\section{Polarizing Airclad Fibers}

Polarization-maintaining fibers are well-known from standard fiber technology and while attractive for many applications, they still require polarized input in an amplifier configuration, and in laser configuration one cannot be certain that there is enough preferential gain to ensure lasing in only one of the polarization directions. These limitations are eliminated in the single-polarization or polarizing fiber in which only one of the polarization states is guided with low loss. Combining low index-step LMA fibers with highbirefringence designs one can obtain polarizing fibers with a wide bandwidth, where the fibers act as traditional polarization maintaining fibers for wavelengths longer than the polarizing cut-off. Figure 2 shows the polarization properties of a large mode area, high NA, airclad fiber containing polarization controlling stress applying parts (SAPs).

The first single-polarization LMA fibers ${ }^{14}$ were designed for $800 \mathrm{~nm}$ operation and featured a $220 \mathrm{~nm}$ broad singlepolarization window and an MFD of $15.5 \mu \mathrm{m}$. Today, stateof-the-art active polarizing designs are defined by the DC200/40-PZ-Yb fiber designed with a birefringence of 1.5 $\times 10^{-4}$ and a polarizing window centered on the operation wavelength at $1060 \mathrm{~nm}$. The core is single mode and has a diameter of $40 \mu \mathrm{m}$ with an NA of 0.03 and the pump cladding diameter is $200 \mu \mathrm{m}$ with an NA of 0.55 . The pump cladding is incorporating two boron-doped regions acting as stress applying parts, producing a single-polarization bandwidth of the fiber of $50 \mathrm{~nm}$. This large mode area fiber has been demonstrated to sustain kilowatt power levels and is designed for high-end pulsed amplifier systems. Figure 3 shows the design of the latest generation DC-200/40-PZ-Yb03 featuring coil control. Coil control automatically ensures that the bending plane of the fiber is fixed. The bending plane is important in this design, as the fiber has different NA in the two orthogonal symmetry directions. Bending the fiber in the wrong plane distorts the mode and introduces bending loss.

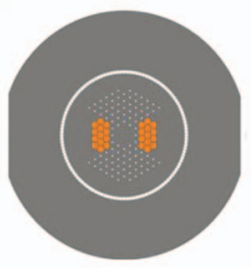

(a)

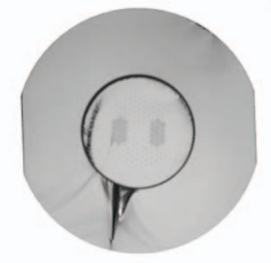

(b)

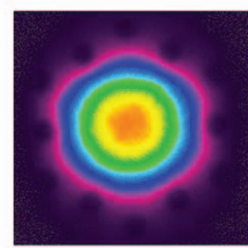

(c)
Fig. 3 Fiber structure of DC-200/40-PZ-Yb-03 fiber with coil control. (a) Schematic of the fiber design illustrating the flat sides on each side of the SAP elements. (b) Optical micrograph picture of the fiber. (c) The mode field diameter is measured to $30 \mu \mathrm{m}$ resulting in a mode field area of $650 \mu \mathrm{m}^{2}$.

The DC-200/40-PZ-Yb-03 is a single-mode fiber and $S^{2}$ on $2.2 \mathrm{~m}$ fiber coiled to $28 \mathrm{~cm}$ shows that the HOM suppression is approximately $25 \mathrm{~dB} .^{15}$

In a pulsed amplifier configuration, this type of fiber has previously been shown to produce high energy pulses. ${ }^{16-18}$ This fiber has been reported to produce up to $90 \mathrm{~W}$ of average power of $500 \mathrm{fs}$ pulses at $0.9 \mathrm{MHz}$ repetition rate corresponding to $100 \mu \mathrm{J}$ of pulse energy. ${ }^{19}$

\section{Rod-Type fibers}

Nonlinear effects is the main limiting factor for the achievable power levels in a fiber amplifier or laser, and as the nonlinear effects are length dependent, it is critical to minimize the fiber length. Shorter fibers require higher pump light absorption per meter, which can be realized by reducing the ratio between the pump core area and the signal core area and by increasing the numerical aperture of the pump guide. Alternatively, one can increase the concentration of rare earths incorporated in the core, but higher concentration has a negative effect on photodarkening and can lead to lower efficiency. Furthermore, extracting large amounts of power from short lengths of fiber requires very good thermal properties. The power extraction will normally be limited by damage of the polymer cladding found in standard double-clad fibers, but the air-glass design of the airclad fiber eliminates this problem. However, both polymer-clad and airclad fibers normally feature a protective coating, which can also be damaged at very high temperatures and reduce the cooling efficiency of the fiber due to the low thermal conductivity of the polymer. This problem can be overcome by simply removing the protective coating and instead make the fiber so thick that it has enough mechanical stability in itself without the protective coating [see Fig. 4(a)]. Moreover, the large outer diameter (typically 1 to $2 \mathrm{~mm}$ ) mitigates another potential problem: macrobending loss. When the core size is expanded beyond 40 to $50 \mu \mathrm{m}$, the index step is so small that the bending radius needed for low loss operation becomes too large for practical systems, but the large diameter of the rod-type fibers ensures the waveguide is not bent, whereby low propagation loss is ensured. The pump absorption of the rod-type fibers is so high (typically on the order of $30 \mathrm{~dB} / \mathrm{m}$ at $976 \mathrm{~nm}$ ) that the system can often be realized with 50 to $70 \mathrm{~cm}$ of fiber making setups built with straight fiber pieces feasibly.

We have previously reported on different types of rod fibers and their use in high-power lasers and amplifiers, ${ }^{20-23}$ the biggest of which featured a $100 \mu \mathrm{m}$ core capable of amplifying to multiple megawatt peak power levels. ${ }^{24}$ One of the 


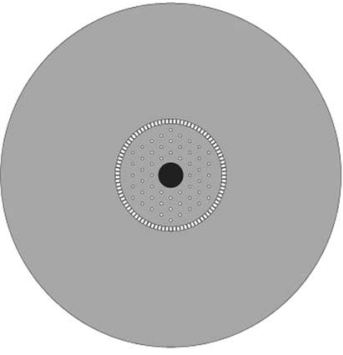

(a)

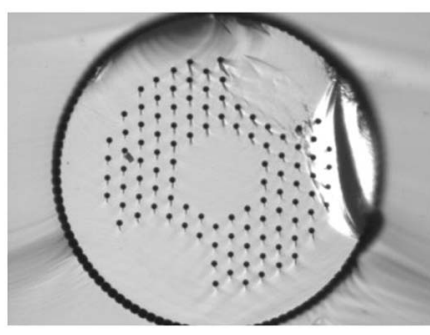

(b)
Fig. 4 (a) Rod-type fiber with increased outer diameter, larger singlemode core, smaller inner cladding and no coating. (b) The new polarization-maintaining DC-285/100-PM-Yb-ROD fiber featuring a $100 \mu \mathrm{m}$ single-mode core and a $285 \mu \mathrm{m}$ multimode pump core.

latest developments is the DC-285/100-PM-Yb-ROD, which, to the best of our knowledge, is the largest polarizationmaintaining fiber in the world, which can be operated in a single mode [see Fig. 4(b)]. The fiber features a $100 \mu \mathrm{m}$ 19-cell core surrounded by a PCF cladding with two imbedded boron-doped regions. The boron regions act as stress applying parts due to their difference in melting point and thermal expansion coefficient compared to the pure silica cladding. Due to the boron contents, the stress applying regions have a lower refractive index than the surrounding silica, thereby contributing to the waveguide. The signal guiding structure is surrounded by a $285 \mu \mathrm{m}$ pump cladding with an NA of 0.6. The fiber has a mode field diameter of approximately $76 \mu \mathrm{m}$ and an NA on the order of 0.02 . The birefringence induced by the boron regions is on the order of $1.5 \times 10^{-4}$.

The newest development features a new design approach for achieving single-mode operation in a large-mode area rod fiber by using a photonic bandgap structure. ${ }^{25}$ The structure allows resonant coupling of higher-order modes from the core and acts as a spatially distributed mode filter (DMF). The fiber cross section of the DMF rod fiber with an $85 \mu \mathrm{m}$ single-mode core is shown in Fig. 5. The rod has been used in a high pulse energy laser. ${ }^{26}$

\section{Airclad Pump Combiners}

Once the challenge of achieving short active fibers with large single-mode cores has been solved, the biggest challenge in the pursuit of a high-power fiber laser system is pump coupling. Several methods of coupling pump light from the diodes into the fiber laser have been developed, including side pumping, ${ }^{27}$ evanescent field coupling, ${ }^{28}$ free space end coupling, and spliced all-fiber end coupling. A spliced end coupling scheme has the advantage of robustness and easier packaging, but gives high demands on the quality of the splices and the thermal management. Moreover, using several pump diodes in a system yields several advantages. Each pump unit can be produced cost efficiently and if one pump fails, it can be taken out and replaced with a simple splice. Furthermore, bar-based pumps on passive heat sinks show an even better lifetime performance than pump sources based on microchannel heat sinks such as stacks of diode bars. ${ }^{29}$ The individual pump sources also have the advantage that amplifier systems can be built using a combiner with a feedthrough fiber.

Fiber coupled diodes are typically delivered in $100 \mu \mathrm{m}$ multimode cores with a down-doped cladding to give an NA



Fig. 5 Rod fiber with DMF elements arranged in a honeycomb-type lattice. The fiber features an $85 \mu \mathrm{m}$ single-mode core.

of 0.22 in the case of fiber coupled bars, or in a $105 \mu \mathrm{m}$ 0.15 NA fiber in the case of single-emitters. To couple the light into a high NA double-clad fiber, the pump fibers must be fused together and the diameter must be reduced in a taper. In a tapered multimode waveguide where the waveguide diameter varies slowly along the length of the device, such changes of NA can take place adiabatic and lossless. Assuming brightness conservation, the NA at the output scales inversely proportional with the output core diameter.

Traditionally, pump combiners have been made by fusing the pump fibers together to a bundle, tapering this bundle down, and finally splicing the tapered end to a polymer cladding delivery fiber. At the location of the taper the light reaches the glass surface and either a glass/air interface or a glass/polymer interface is guiding the light. In general, the

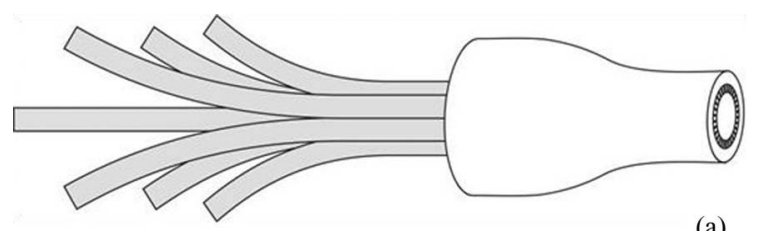

(a)

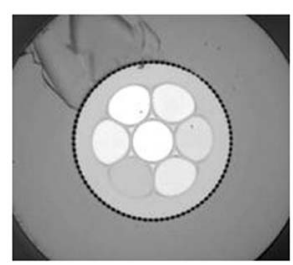

(b)

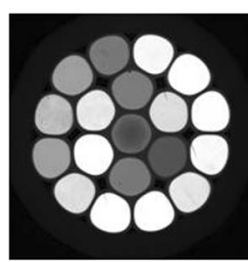

(c)
Fig. 6 (a) Schematic example of an airclad-based combiner. The multimode pump fibers (left) are fused together and tapered down. The light from the tapered bundle is captured by the surrounding airclad and guided to the end of the device without ever reaching the surface. (b) Example of a fused bundle of seven multimode fibers surrounded by an air-clad and (c) of 19 fused fibers before the airclad. 
challenge of using standard polymer-clad fused pump combiners for high-power is the light absorbed in the polymer coating and the adhesive used in the package. ${ }^{30}$ Since modestripping cannot easily be employed, challenges due to local heating must be addressed.

The technique for making an airclad combiner is similar to the description above: a fiber bundle is made by fusing several pump fibers together under high temperatures to form a solid element. If the fusing is done in a well-controlled manner, the multimode cores still guide individually and conserve the NA of the light launched. In our novel combiner concept, once tapering takes place, an airclad is used to maintain waveguiding of the increased NA light (see Fig. 6). An airclad delivery fiber is spliced to the tapered waveguide to finalize the optical device using cold splicing techniques in order to avoid collapsing the airclad. The inner cladding diameter of the delivery fiber is determined by the number of input fibers and the desirable output NA (typically 0.55 to 0.65 when designed for use with an active airclad fiber).

An important difference between the airclad combiner and the standard combiner is that the light in the airclad combiner propagates in a waveguide with a glass cladding at all points along the device, either through index guiding in the individual cores (at the input) or confined by the airclad (at the output). Since the light never reaches the surface of the device, it is insensitive to mechanical contact and to cleanliness in general. In comparison, for pump combiners based on polymer cladding fiber technology, at least the tapered part of the combiner must be kept absolutely clean at all times, since any contamination on the surface will lead to scattering, heating, and possibly failure of the device. One challenge related to airclad combiners is that cold splices in the combiners make them fragile, but this can be addressed by proper handling.

The fact that we are able to mechanically contact to any point on the outer surface of the cladding was utilized to include a mode-stripper in the device by roughening of the fiber surface. The purpose of a mode-stripper is to scatter unwanted cladding guided light out of the device before it reaches the coating of the active fiber.

We have, so far, realized combiners with 7 and 19 ports of $100 \mu \mathrm{m} 0.22 \mathrm{NA}$ input fibers which have been tested to a power level in excess of $350 \mathrm{~W}$. The typical device loss is 0.1 to $0.2 \mathrm{~dB}$ corresponding to $95 \%$ to $98 \%$ transmission. The low loss simplifies thermal management as the combiners can be operated uncooled even at several hundred watts. If the combiners are sufficiently cooled, they should be able to handle in excess of $1 \mathrm{~kW}$ of pump power. With a conservative $5 \%$ transmission loss, $50 \mathrm{~W}$ of heating power need to be dissipated. There are several reasons why we believe this to be realistic:

- Due to the mode-stripper, lost light is not absorbed, but rather scattered out and away from the device. This means that heating is not taking place locally, reducing the presence of hot-spots.

- The combiner is an all-silica device containing no polymers. Such a device can tolerate significantly higher temperatures than other combiners containing polymers before any risk of degradation.

- Dissipating $50 \mathrm{~W}$ can easily be done by forced air cooling. Using a water-cooled plate allows much higher powers to be dissipated.

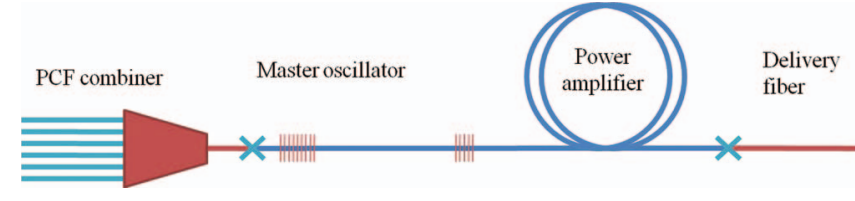

Fig. 7 Configuration of the monolithic splice-free MOPA configuration. The Bragg gratings are written directly in the Yb-doped airclad fiber eliminating intracavity splices and thereby improving efficiency and reliability. The system is pumped through and airclad combiner $(1: 1,7: 1$, or $19: 1)$ spliced to the active fiber and the output is delivered through a step-index single-mode fiber.

Based on the optical performance of the $7 \times 1$ and $19 \times 1$ combiner at high powers, we estimate that the airclad combiner concept will allow the power in each input port to be increased to at least $100 \mathrm{~W}$.

\section{Airclad Fiber Lasers}

Bringing together the active PCFs and the airclad pump combiners described above, we have realized an airclad fiber laser module in the form of the aeroLASE-350. The aeroLASE-350 features a completely monolithic splice-free master oscillator power amplifier (MOPA) configuration (see Fig. 7) with standard fiber interfaces. The high reflector has a reflectivity of $>98 \%$ and a bandwidth of $800 \mathrm{pm}$, while the output coupler has a reflectivity of $\sim 30 \%$ and a bandwidth of $600 \mathrm{pm}$. The active fiber has a mode field diameter of $15 \mu \mathrm{m}$. Due to the splice free configuration, the intracavity losses are very low and the system efficiency is more than $60 \%$ at the design power level of $350 \mathrm{~W}$ (see Fig. 8). The beam quality of the system is excellent with an $M^{2}$ of less than 1.1 (see Fig. 9). The system consists of an airclad pump combiner $(1: 1,19: 1$, or $61: 1)$ spliced to a photosensitive ytterbiumdoped airclad fiber. The cavity is formed by two Bragg gratings written directly in the airclad fiber. The gratings are written in one end of the fiber forming the master oscillator, while the remaining fiber forms the power amplifier, which is pumped through the master oscillator. The signal is delivered through a step-index fiber spliced to the output of the power amplifier.

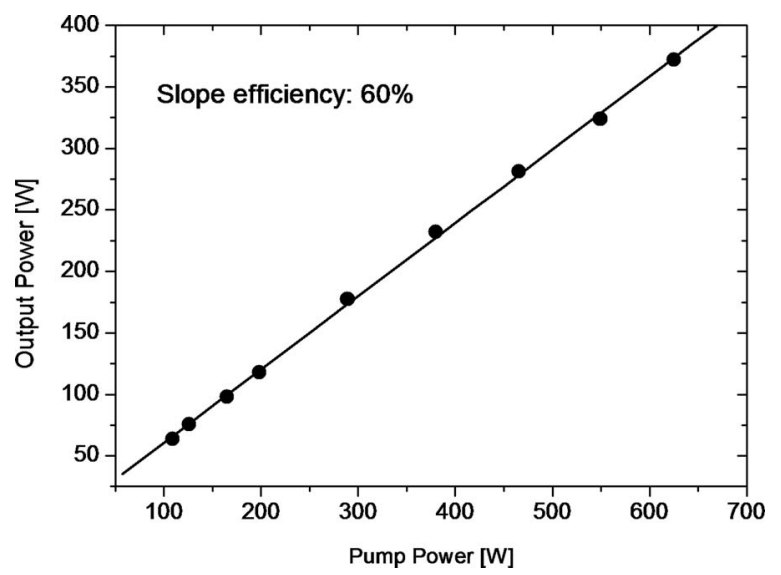

Fig. 8 Output power from the delivery fiber versus lunched pump power. The lasing threshold is approximately 1 to $2 \mathrm{~W}$ indicating extremely low intracavity losses. The slope efficiency is approximately $60 \%$. The system is pumped with a $800 \mathrm{~W}$ LaserLine $915 \mathrm{~nm}$ system through a 1:1 airclad taper. 


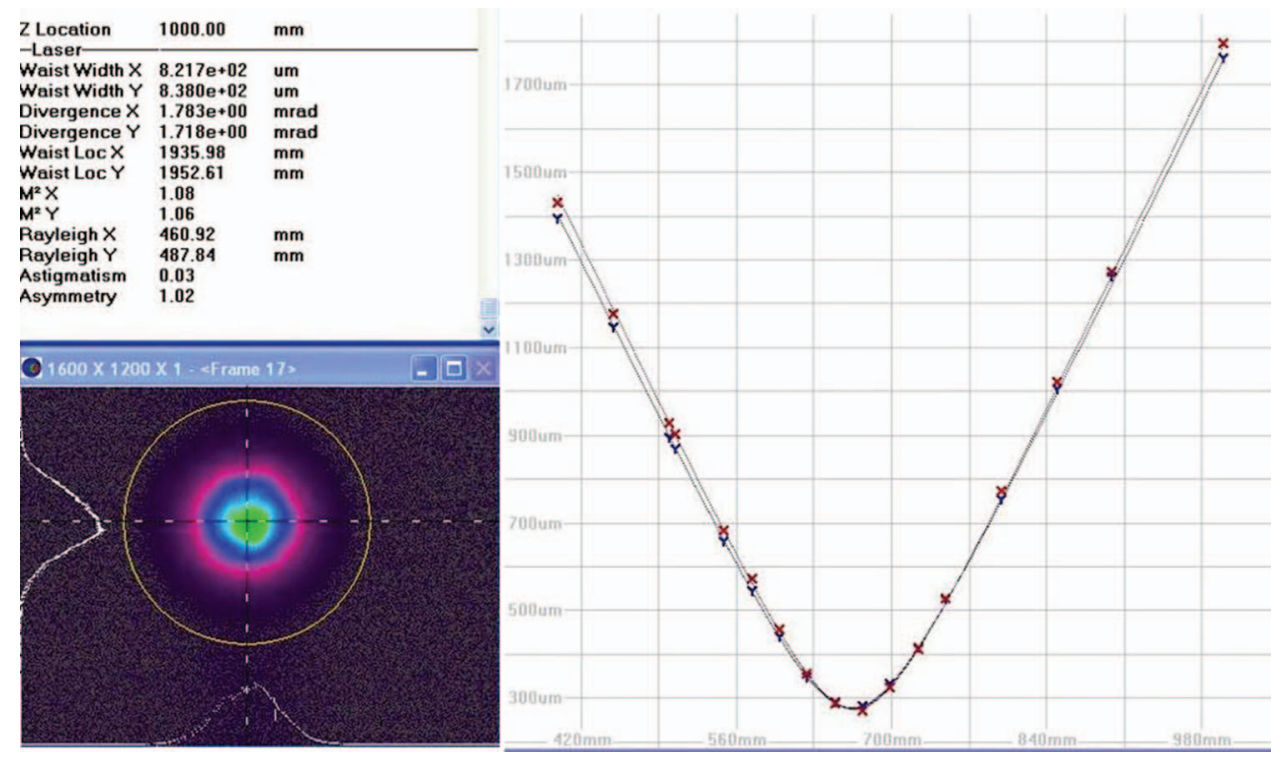

Fig. $9 \mathrm{M}^{2}$ measured on the system at $200 \mathrm{~W}$ output power with a Spiricon mode profiler. The beam quality is close to the theoretical limit for single-mode fibers with $M_{X}^{2}=1.08$ and $M_{Y}^{2}=1.06$ and is independent of the output power.

The splice-free MOPA configuration has several advantages. Low intracavity losses ensure high efficiency and a low lasing threshold (the system starts lasing in stable $\mathrm{cw}$ mode at a pump power on the order of 1 to $2 \mathrm{~W}$ ). Moreover, the simple configuration increases the reliability of the system as splices and pump coupling points are traditionally weak points in a fiber laser.

The low threshold and stable operation enables quasi-cw configurations with directly modulated pump diodes, which is attractive for many material processing applications. The configuration has been tested with diodes driven by square pulses at $100 \%$ modulation depth and up to $10 \mathrm{kHz}$ repetition rate with excellent results.

The system is designed to operate at $350 \mathrm{~W}$, but in order to explore the power limitations the aeroLASE-350 was tested to beyond $500 \mathrm{~W}$ output (pump power limited). The configuration was pumped through a 1:1 airclad taper with an $800 \mathrm{~W}$ LaserLine pump module operating at $915 \mathrm{~nm}$. We measured the linewidth of the output at 100, 250, and $500 \mathrm{~W}$ (see Fig. 10), and even at full power the output is free of side-bands and the linewidth is less than 200 pm, indicating that the system is running far from the nonlinear limit. The center wavelength changes approximately $0.5 \mathrm{~nm}$ from 100 to $500 \mathrm{~W}$ output, which is due to heating of the Bragg gratings. The gratings are heat sunk to the same cooling plate as the active fiber, but with active temperature control of the gratings (e.g., using Peltier coolers) one could stabilize the center wavelength.

So far, the system has been tested for more than $1000 \mathrm{~h}$ and the efficiency is approximately 55\% (down from just above $60 \%$ efficiency at the beginning). After an initial small drop in power, the output signal has stabilized and no further degradation is observed, and the system lifetime is expected to be well beyond $10.000 \mathrm{~h}$. This performance is obtained through a combination of a low-inversion level configuration and fibers with photodarkening optimized core materials minimizing color center generation. Further improvements to the active materials are expected to bring the efficiency at $10.000 \mathrm{~h}$ above $60 \%$.

\section{Airclad Pump/Signal Combiners}

Pump combiners with a signal feed-through are essential components for making all fiber-based amplifiers. Such components have been commercially available for several years for the polymer cladding fibers, ${ }^{31-33}$ but only recently have they been demonstrated in all air-clad fiber-based designs. ${ }^{34}$ The airclad pump/signal combiner is based on a $7+1$ to 1 configuration that features a $15 \mu \mathrm{m}$ MFD signal feedthrough and is used for pulse amplification in a backward pumped configuration. Figure 11(a) shows the layout of the combiner. The pump fibers are $105 \mu \mathrm{m}$ core fibers and the combiner is designed for 0.15 NA pump diodes. The signal fiber is single-mode (SM) and polarization-maintaining (PM) with a higher order mode cutoff at $\sim 980 \mathrm{~nm}$, an MFD of $15 \mu \mathrm{m}$, and a cladding diameter of $160 \mu \mathrm{m}$. The signal and pump fibers are fused together to form a fiber bundle with the signal fiber in the center surrounded by the seven pump fibers.

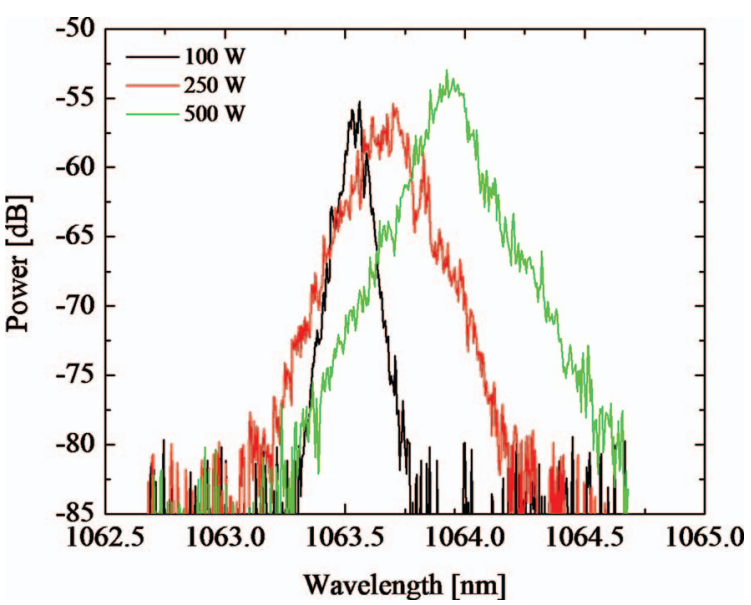

Fig. 10 Linewidth of the system at 100, 250, and $500 \mathrm{~W}$ output power. The linewidth at full $500 \mathrm{~W}$ power is below $200 \mathrm{pm}$. Moreover, the output is completely free of side bands indicating that the system is operating far below the nonlinear threshold. 


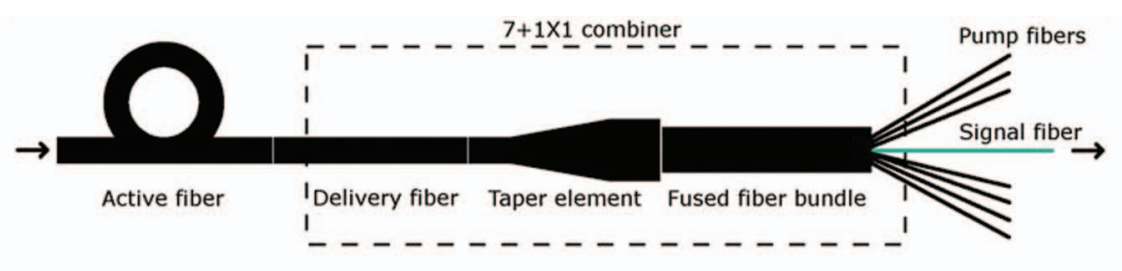

(a)

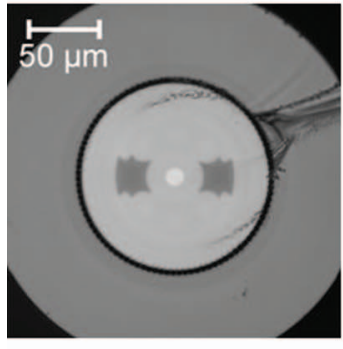

(b)



(c)



(d)

Fig. 11 (a) Illustration of fused $7+1 \times 1$ pump/signal combiner. The combiner is designed for backward pumping of the active fiber. (b) Microscope cross sectional image of the passive double-clad delivery fiber. (c) Microscope cross sectional image of the taper element. (d) Microscope cross sectional image of the fused fiber bundle.

Figure 11(d) shows a microscope cross sectional image of the fused fiber bundle. The passive double-clad delivery fiber has an SM and PM signal core with a $15 \mu \mathrm{m} \mathrm{MFD} \mathrm{and} \mathrm{an} \mathrm{innner}$ cladding diameter of $133 \mu \mathrm{m}$. Figure 11(b) shows a cross sectional image of the delivery fiber. The air-cladding of the fiber can be seen as the ring of closely spaced holes surrounding the fiber core. To ensure efficient coupling of signal and pump to the passive double-clad delivery fiber, an intermediate waveguide section is used. This intermediate section, called a taper element, is a fiber with a complex waveguiding structure. The untapered end of the taper element is spliced to the fiber bundle and the tapered end is spliced to the double-clad delivery fiber. The function of the taper element is both to merge pump and signal light into the double-clad fiber, but also via the taper to increase the intensity of the pump by reducing the pump guide area. This increases pump absorption in the active fiber and thereby the efficiency of the pumping. The air-cladding of the taper element handles this coupling of the pump light. The signal coupling is done through the signal core of the taper element that consists of a concentric dual-core structure, with an SM step-index core surrounded by two rings of air-holes. On either side of the core an air-hole is replaced with a boron stress rod in order to ensure PM operation. Figure 11(c) shows a microscope image of the center part of the taper element. In the untapered end of the taper, the element light will be guided in the SM step-index core. In the tapered end, light will be guided in a core defined by the air-hole PCF structure. In the tapered region light is coupled adiabatically between the two cores, thereby remaining guided in an SM waveguide throughout the taper. In order to illustrate the signal guidance through the taper element, Fig. 12 shows a calculation of the MFD in the taper element as a function of distance between the air-holes (pitch), as well as the measured MFD at different positions along the taper.

The realized combiners have a typical average pump transmission loss of 0.1 to $0.3 \mathrm{~dB}$, a transmission loss of the signal of $<0.60 \mathrm{~dB}$, and a polarization cross talk for the signal of $<-18 \mathrm{~dB}$. The active fiber that the combiner is matched to is the DC-135/15-PM-Yb airclad fiber. With the combiner spliced to this fiber and the active fiber spliced to a seed source, a full all fiber-based amplifier chain is realized. Figure 13 shows the measured slope efficiency of such an amplifier. The amplifier system was seeded with 10 ps pulses, with a repetition rate of $80 \mathrm{MHz}$ and an average power of $100 \mathrm{~mW}$. A 54\% conversion efficiency is measured. The peak power of the pulses is also shown in Fig. 13 on the right axis. An average power of $18 \mathrm{~W}$ and a peak power of $23 \mathrm{~kW}$ was achieved, with a signal to Raman noise level of $-35 \mathrm{~dB}$. A perfect SM signal out of the amplifier is obtained. This is due to the combiner and signal fiber that are strictly SM, with the latter having a higher order mode cutoff at $\sim 980 \mathrm{~nm}$. The $M^{2}$ value of the signal is measured to be $<1.1$ measured at an average power out of the amplifier of $18 \mathrm{~W}$.

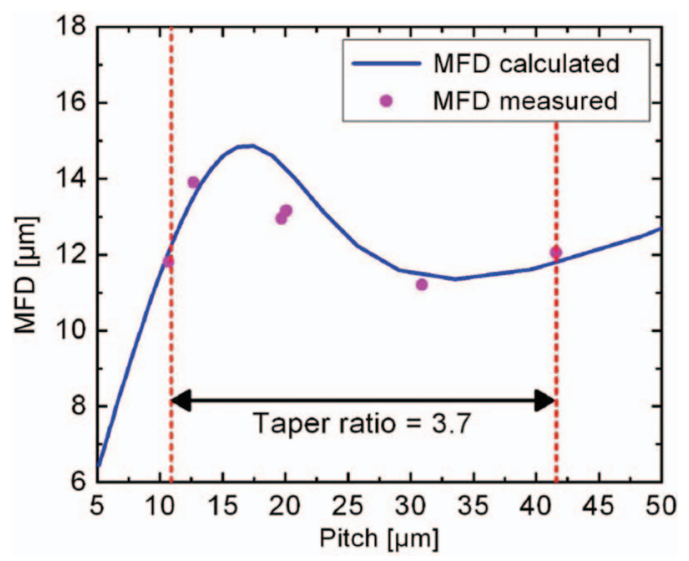

Fig. 12 MFD as a function of taper element pitch. The dashed lines indicate the pitch of the taper element in the tapered and untapered end of the combiner. 


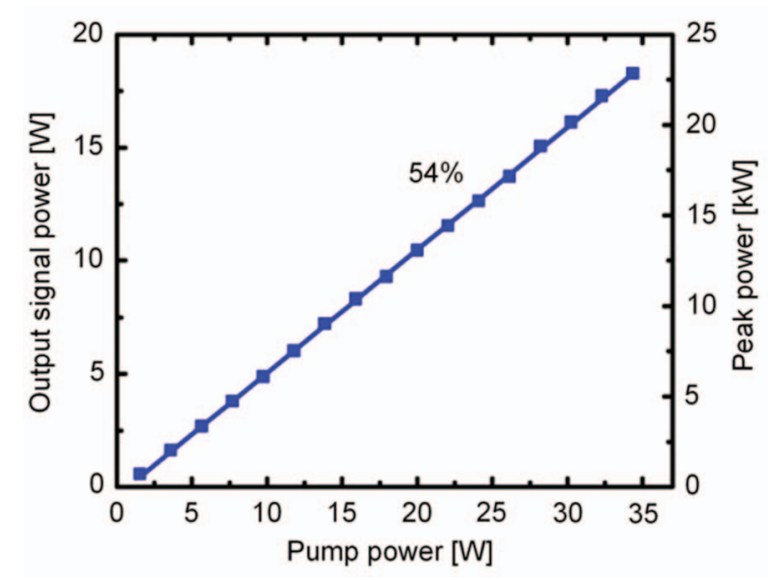

Fig. 13 Slope efficiency of amplifier system with $5 \mathrm{~m}$ of active fiber spliced to the $7+1$ to 1 combiner.

\section{Conclusion}

The advantages of high-power fiber lasers are no longer an issue of discussion, and the attention of the laser community has now turned to the challenge of how to achieve those advantages at highest possible power levels. The airclad fiber technology is a compelling alternative to the standard polymer-clad fibers as they offer large single-mode cores and higher pump cladding NA, thereby enabling shorter devices with excellent high-power performance.

The PCF technology has pushed the boundaries for single-mode fibers and we have demonstrated a polarizationmaintaining $100 \mu \mathrm{m}$ core rod-type fiber for pulsed MW-class high energy systems featuring a mode area of more than $4500 \mu \mathrm{m}^{2}$. In addition, we have shown how the single-mode PCF LMA design can be combined with stress element to realize polarizing amplifier fibers, guiding only one state of polarization-bendable fibers capable of amplifying to the $1 \mathrm{MW}$ peak power level without nonlinear effects. Lasers based on these fibers excel in particular for high-power systems where stability of beam quality is key.

Short large core fibers are only one side of the equation when building a high-power laser system; equally important is stable coupling of the pump power, especially when operating at several hundreds of watts. Many of the commercially available laser systems today rely on a distributed coupling scheme as fused pump combiners capable of delivering the required pump power in an end-pump scheme has not previously been available. This has changed with the airclad pump combiners. This new type of combiner offers very low loss and high thermal stability. We have demonstrated $1 \times 1$, $7 \times 1$, and $19 \times 1$ combiners tested to beyond $350 \mathrm{~W}$ of pump power. However, based on the low loss and low thermal load on the devices, we expect these combiners to be able to handle kilowatt power levels, bringing the simple end-pumped fiber lasers into the high-power regime.

Using the described fibers and airclad combiners, we have realized a completely monolithic fiber laser system (the aeroLASE-350), which has been tested to above $500 \mathrm{~W}$ output power with perfect beam quality $\left(M^{2}<1.1\right)$ and narrow linewidth (below $200 \mathrm{pm}$ at $500 \mathrm{~W}$ ). The simple MOPA configuration contains no intracavity splices resulting in high reliability and efficiency above $60 \%$.

\section{References}

1. E. Snitzer, H. Po, F. Hakimi, R. Tumminelli, and B. C. McCollum, "Double clad, offset core Nd fiber laser," in Proceedings of Optical Fiber Sensors Conference, PD 5, New Orleans (1988).

2. V. Bhagavatula, R. Bhat, G. E. Berkey, X. Chen, M. J. Dejneka, M. Gallagher, L. C. Hughes, K. W. Koch, J. Koh, M. J. Li, X. Liu, D. A. Nolan, M. H. Rasmussen, C. L. Tennent, N. Venkataraman, D. T. Walton, J. Wang, C. E. Zah, and L. A. Zenteno, "Progress in high power fiber lasers," in Proceedings of Photonics West, Invited paper 5335-30, San Jose, California (2004)

3. J. LeGrange, E. Vogel, K. Quoi, D. J. DiGiovanni, A. Hale, R. Pedrazzani, and T. Strasser, "Optical reliability of cladding pump fiber for high power communication networks," in Proceedings of Military Communication Conference, 23.3 (1999)

4. J. Limpert, T. Schreiber, A. Liem, S. Nolte, H. Zellmer, T. Peschel, V. Guyenot, and A. Tünnermann, "Thermo-optical properties of air-clad photonic crystal fiber lasers in high power operation," Opt. Express 11, 2982-2990 (2003).

5. J. M. Fini, "Bend distortion in large-mode-area amplifier fiber design," Proc. SPIE 6781, 6781E (2007).

6. N. A. Mortensen, J. R. Folkenberg, M. D. Nielsen, and K. P. Hansen, "Modal cut-off and the V-parameter in photonic crystal fibers," Opt. Lett. 28, 1879-1881 (2003)

7. T. A. Birks, J. C. Knight, and P. S. Russell, "Endlessly single-mode photonic crystal fiber," Opt. Lett. 22, 961-963 (1997).

8. N. A. Mortensen and J. R. Folkenberg, "Low-loss criterion and effective area considerations for photonic crystal fibers," J. Opt. A: Pure Appl. Opt. 5, 163-167 (2003).

9. M. D. Nielsen, J. R. Folkenberg, and N. A. Mortensen, "Singlemode photonic crystal fiber with effevtive area of $600 \mu \mathrm{m}^{2}$ and low bending loss," Electron. Lett. 39, 1802-1803 (2004).

10. M. D. Nielsen, G. Vienne, J. R. Folkenberg, and A. Bjarklev, "Investigation of microdeformation-induced attenuation spectra in a photonic crystal fiber," Opt. Lett. 28, 236-238 (2002).

11. M. D. Nielsen, N. A. Mortensen, and J. R. Folkenberg, "Reduced microdeformation attenuation in large-mode-area photonic crystal fibers for visible applications," Opt. Lett. 28, 1645-1647 (2003).

12. S. Wielandy, "Implications of higher-order mode content in large mode area fibers with good beam quality," Opt. Express 15, 15402-15409 (2007).

13. J. W. Nicholson, A. D. Yablon, S. Ramachandran, and S. Ghalmi, "Spatial and spectrally resolved imaging of modal content in large-mode-area fibers," Opt. Express 16(10), 7233-7243 (2008).

14. J. R. Folkenberg, M. D. Nielsen, and C. Jakobsen, "Broadband singlepolarization photonic crystal fiber," Opt. Lett. 30, 1446-1448 (2004).

15. M. Laurila, T. T. Alkeskjold, J. Laegsgaard, and J. Broeng, "Spatial and spectral imaging of LMA photonic crystal fiber amplifiers," Proc. SPIE 7914, 79142D (2011).

16. C. D. Brooks and F. Di Teodoro, "1-mJ energy, 1-MW peak-power, 10 -W average-power, spectrally narrow, diffraction-limited pulses from a photonic-crystal fiber amplifier," Opt. Express 13, 8999-9002 (2005).

17. L. Shah, Z. Liu, I. Hartl, G. Imeshev, G. C. Cho, and M. E. Fermann, "High energy femtosecond Yb cubicon fiber amplifier," Opt. Express 13, 4717-4722 (2005).

18. F. Röser, J. Rothhardt, B. Ortac, A. Liem, O. Schmidt, T. Schreiber, J. Limpert, and A. Tünnermann, "131 W 220 fs fiber laser system," Opt. Lett. 30, 2754-2756 (2005).

19. F. Röser, D. Schimpf, O. Schmidt, B. Ortac, K. Rademaker, and J. Limpert, "90-W average-power, high-energy femtosecond fiber laser system," Proc. SPIE 6453, 645310 (2007).

20. J. Limpert, N. Deguil-Robin, I. Manek-Hönninger, F. Salin, F. Röser, A. Liem, T. Schreiber, S. Nolte, H. Zellmer, A. Tünnermann, J. Broeng, A. Petersson, and C. Jakobsen, "High power rod-type photonic crystal fiber laser," Opt. Express 13, 1055-1058 (2005).

21. F. Di Teodoro and C. D. Brooks, "Very large-core, single-mode Ybdoped photonic-crystal rod for multi-MW peak power generation," in Proceedings of Photonics West, 6102-13, San Jose, California (2006).

22. J. Limpert, O. Schmidt, J. Rothhardt, F. Röser, T. Schreiber, and A. Tünnermann, "Extended single-mode photonic crystal fiber lasers," Opt. Express 14, 2715-2720 (2006).

23. J. Limpert, N. Deguil-Robin, I. Manek-Hõnninger, F. Salin, F. Röser, A. Liem, T. Schreiber, S. Nolte, H. Zellmer, A. Tünnermann, J. Broeng, A. Petersson, and C. Jakobsen, " $120-\mathrm{W}$ short-length rod-type photonic crystal fiber laser," in Proceedings of Conference on Lasers and Electro Optics, CLEO, 819-821 (2005).

24. C. D. Brooks and F. Di Teodoro, "Multimegawatt peak-power, singletransverse-mode operation of a $100 \mu \mathrm{m}$ core diameter, Yb-doped rodlike photonic crystal fiber amplifier," Appl. Phys. Lett. 89, 111119 (2006).

25. T. Tanggaard Alkeskjold, M. Laurila, L. Scolari, and J. Broeng, "Singlemode ytterbium-doped large-mode-area photonic bandgap rod fiber amplifier," Opt. Express 19, 7398-7409 (2011).

26. M. Laurila, J. Saby, T. T. Alkeskjold, L. Scolari, B. Cocquelin, F. Salin, J. Broeng, and J. Lægsgaard, "Q-switching and efficient 
harmonic generation from a single-mode LMA photonic bandgap rod fiber laser," Opt. Express 19, 10824-10833 (2011).

27. L. Goldberg, "Method and apparatus for side pumping an optical fiber," U.S. Patent No. 5,854,865 (1998)

28. S. Norman, M. Zervas, A. Appleyard, P. Skull, D. Walker, P. Turner, and I. Crowe, "Power scaling of high power fiber lasers for micromachining and materials processing applications," Proc. SPIE 6102, 61021P (2006).

29. G. Bonati, P. Hennig, D. Wolff, H. Voelckel, T. Gabler, U. Krause, A. Tünnermann, M. Reich, J. Limpert, E. Werner, and A. Liem, "High power diode laser bars as pump sources for fiberlasers and amplifiers," in Proceedings of Photonics West, pp. 78, San Jose, California (2005).

30. F. Séguin, A. Wetter, L. Martineau, M. Faucher, C. Delisle, and S. Caplette, "Tapered fused bundle coupler package for reliable high optical power dissipation," Proc. SPIE 6102, 61021N (2006).
31. F. Gonthier, L. Martineau, N. Azami, M. Faucher, F. Séguin, D. Stryckman, and A. Villeneuve, "High-power all-fiber components: The missing link for high power fiber lasers," Proc. SPIE 5335, 266-276 (2004).

32. M. Nakai, K. Shima, M. Saito, and T. Kitabayashi, "30W Q-SW fiber laser," Proc. SPIE 6453, 645319 (2007)

33. V. Gapontsev and I. Samartsev, "Coupling arrangement between a multimode light source and an optical fiber through an intermediate optical fiber length," U.S. Patent No. 5,999,673 (1999).

34. D. Noordegraaf, M. D. Nielsen, P. M. W. Skovgaard, S. Agger, T. T. Alkeskjold, and J. Lægsgaard, "7+1 to 1 pump/signal combiner for air-clad fiber with 15 m MFD PM single-mode signal feed-through," Proc. SPIE 7580, 75801A (2010).

Biographies and photographs of the authors are not available. 